\title{
Re-Laparotomy after Caesarean Section at Omdurman Maternity Hospital-Khartoum, Sudan
}

\author{
Atif Bashir Fazari1,2*, N. S. Eldeen³, W. Mohammed1, M. Muror'2, E. Gailii1,2 \\ ${ }^{1}$ Reproductive and Child Health Research Unit, University of Medical Sciences \& Technology, Khartoum, Sudan \\ ${ }^{2}$ Omdurman Maternity Hospital, Ministry of Health, Khartoum, Sudan \\ ${ }^{3}$ Elhasahesa Teaching Hospital, Gezira, Sudan \\ Email: ${ }^{*}$ atiffazari@hotmail.co.uk
}

Received 3 June 2015; accepted 18 August 2015; published 21 August 2015

Copyright (C) 2015 by authors and Scientific Research Publishing Inc.

This work is licensed under the Creative Commons Attribution International License (CC BY).

http://creativecommons.org/licenses/by/4.0/

(c) (;) 0pen Access

\section{Abstract}

Introduction: Caesarean section has avoidable morbidity which may lead to mortality especially in developing world. Caesarean section is a major operation which should be performed with maximum care and safety. Objectives: This study aimed to find incidence, indications, procedures and maternal outcome of re-laparotomy after caesarean delivery. Methods: This was a descriptive cross sectional prospective total coverage hospital based study conducted at Omdurman Maternity Hospital from June 2014 to January 2015. Results: The incidence for re-laparotomy after Caesarean section is $(0.66 \%)$ and the main indication for re-laparotomy is hemorrhagic events. Relaparotomy outcome reported 22 cases (64.7\%) alive and well and 6 cases (17.6\%) alive with morbidity (renal failure and massive blood transfusion complications) and 6 cases (17.6\%) of maternal mortality mainly due to sepsis. Conclusion: Re-laparotomy after Caesarean section is contributing to morbidity and maternal mortality. The majority of re-laparotomy was done after emergency Caesarean section. Lacks of skills, experience; safety measures of perfection and infection control are points to be concern.

\section{Keywords}

Re-Laparotomy, Caesarean Section, Maternal Morbidity, Maternal Mortality

\section{Literature Review}

Re-laparotomy (RL) after Caesarean section refers to laparotomy perform for the original disease within 60 days

\footnotetext{
${ }^{*}$ Corresponding author.
}

How to cite this paper: Fazari, A.B., Eldeen, N.S., Mohammed, W., Muror, M. and Gailii, E. (2015) Re-Laparotomy after Caesarean Section at Omdurman Maternity Hospital-Khartoum, Sudan. Open Journal of Obstetrics and Gynecology, 5, 448-454. http://dx.doi.org/10.4236/ojog.2015.58065 
from the first operation, where as the term "early re-laparotomy" refers to laparotomy performed for the original disease within 21 days of the first operation [1]. Caesarean section (C/S) is the most common obstetric operation carried out in daily obstetric practice and the incidence has shown a dramatic increase over the last years. With the improvement of operative technologies, anesthesia coverage, blood transfusion facilities and safety of Caesarean section have increased considerably. Still it is a major operation and is associated with certain risk and complication [2].

In developing world, Caesarean section has many avoidable risks and morbidity and not all safety measures are available in most of the facilities especially the rural areas.

Early recognition and treatment of post operative complications which can necessitate surgical re-operation are important in order to achieve a successful outcome.

Re-laparotomy is indicated when there is: Postpartum hemorrhage ( $\mathrm{PPH})$, internal bleeding, visceral injury, peritonitis, burst abdomen and foreign body.

The stability of the patient determines the need for expedient operative management. Usually, it is an emergency because more conservative measures have failed. Once the need for re-operation is apparent, it is necessary to summon the operating room staff and anesthesia. They should be informed of the urgent need for re-operation [3].

Postpartum hemorrhage is a serious obstetric emergency and a leading cause of maternal morbidity and mortality. Although identification of risk factors before and during labor is important, significant life threatening bleeding can occur in the absence of risk factors and without warning [4].

Peritonitis is a common emergency encountered by surgeons' world over. Secondary peritonitis is caused by loss of integrity of viscous due to infection, ischemic necrosis, trauma or peritonitis occurring as a result of postoperative complications. Source control in the form of surgical or percutaneous drainage is the mainstay of treatment [5].

Bladder injury is possible in any standard lower segment Caesarean section. This is due to the nature of the operation itself. Thus, bladder injury and disturbed urinary function are well-known risks of caesarean section. However, the risks are significantly increased in the second stage Caesarean section, as the operation is much more difficult to perform than an elective Caesarean section, or a Caesarean section performed in first stage of labor [6].

Despite the close anatomical association between the female reproductive organs and the ureter, injury to the ureter is relatively uncommon. Nevertheless, when a ureteric injury does occur, quick recognition of the problem and a working knowledge of its location and treatment are essential in providing patients with optimal medical care [7].

In rare cases, bowel injury after Caesarean section may occur. A few types of bowel injuries that can happen during this procedure include burns or perforation injuries. Usually, these injuries can be treated fairly easily; however, if the bowel injury after Caesarean section is serious, other surgical procedures may be required [8].

Wound Dehiscence is the premature "bursting" open of a wound along surgical suture. It is a surgical complication that results from poor wound healing. Risk factors in general are anaemia, diabetes, obesity, poor knotting or grabbing of stitches and trauma to the wound after surgery.

Abdominal wound dehiscence (burst abdomen, facials dehiscence) is a severe postoperative complication, with mortality rates reported as high as $45 \%$. The incidence as described in the literature ranges from $0.4 \%$ to $3.5 \%$, in study was done in India in 2010 [9].

The procedures which should be taken during re-laparotomy after Caesarean section like: Hysterectomy, Bilateral uterine artery ligation, Internal iliac artery ligation, Drainage of blood clot from under surface of rectus sheath, re-suturing of uterine incision, removal of foreign body, tension suture, repair of anterior abdominal wall, bladder repair, repair of the bowel injury [10] [11].

Re-laparotomy increases risk of maternal morbidity and maternal mortality because of lack of appreciation of blood loss which must have more than estimated, anesthetic complications septicemia and multi organ failure. Those who survived also developed post operative complications in the form of failure of lactation, renal failure managed with dialysis, septicemia, wound infection, febrile morbidities, peritonitis and brain insult due to anesthesia, bladder injury, bowel injury and hysterectomy [12].

\section{Objectives}

This study aimed to find incidence, indications of re-laparotomy following Caesarean delivery, procedures done 
in re-laparotomy and maternal out come after re-laparotomy in Omdurman Maternity Hospital between June 2014 to January 2015.

\section{Methodology}

This was a descriptive cross sectional prospective total coverage hospital based study conducted at Omdurman Maternity Hospital from June 2014 to January 2015. Omdurman Maternity Hospital is first and largest specialized maternity hospital in Sudan. It was established in 1957. It runs obstetrics \& gynecology services and training. 36,500 deliveries are registered annually.

Once decision for re-laparotomy is taken and after the consent, the cases enrolled in our study lucky enough all are agreed.

The investigators are involved in data collection using specific designed data collection sheet designed for this purpose. This sheet includes case's demographic variables, indication for re-laparotomy, intra-operative findings, procedure done for the case, hospital stay and the maternal outcome are the main variables of concern. Data were analyzed by computer using statistical package for social science (SPSS) software and the results are expressed in tables and figure.

Ethical approval was obtained from the Ethical Committee at Sudan Medical Specialization Board and proved by signed agreement from the medical director of the hospital. Inform verbal consent was obtained from cases or guardian. The confidentiality was granted throughout and after the study.

\section{Results}

The total number of patient who had Caesarean Caesarean section during the period of the study was 5158 out of total registered deliveries 18,989 (27.1\%) in Omdurman Maternity Hospital during study period, 34 patients gives an incidence of $(0.66 \%)$ for re-laparotomy after $\mathrm{C} / \mathrm{S}$.

Concerning the age of the patients, re-laparotomy mainly was in age group between 30 - 34 years in 13 cases, (38.2\%) followed by the age group between 25 - 29 years in 9 cases (26.5\%) and there were 5 cases (14.7\%) in the age group between 20 - 24 years and 4 cases (11.8\%) in the age group between 15 - 19 years.

With regards to parity, re-laparotomy was common in multipara 20 cases, (58.8\%) followed by primigravida, 12 cases (35.3\%). 2 cases (5.9\%) in grandmultipara.

In 29 cases (85.3\%) The re-laparotomy followed emergency Caesarean section and 5 cases (14.7\%) followed elective Caesarean section.

Table 1 shows the indications of re-laparotomy after Caesarean section in this study was internal hemorrhage in 15 cases (44\%) followed by PPH in 5 cases (14.7\%) and peritonitis in 5 cases (14.7\%). There were 3 cases (8.8\%) of burst abdomen. 2 cases (5.9\%) of rectus sheath hematoma. 1 case (2.9\%) of removal of foreign body, 1 case (2.9\%) of Removal of packed gauze, 1 case (2.9\%) of bladder injury, 1 case (2.9\%) of ovarian accident.

Table 1. Distribution of re-laparotomy after Caesarean delivery in Omdurman maternity hospital from June 2014-January 2015 according to the indications of re-laparotomy after $\mathrm{C} / \mathrm{S}(\mathrm{N}=34)$.

\begin{tabular}{|c|c|c|}
\hline Indicatins of re-laparotomy after C/S & Frequency & Percent \\
\hline $\mathrm{PPH}$ & 5 & 14.7 \\
\hline Internal haemorrhage & 15 & 44.1 \\
\hline Peritonitis & 5 & 14.7 \\
\hline Burst abdomen & 3 & 8.8 \\
\hline Removal of forign body & 1 & 2.9 \\
\hline Removal of packed gauze & 1 & 2.9 \\
\hline Rectus sheath haematoma & 2 & 5.9 \\
\hline Ovarian accident & 1 & 2.9 \\
\hline Bladder injury & 1 & 2.9 \\
\hline Total & 34 & 100.0 \\
\hline
\end{tabular}


Concerning the procedures which were done in re-laparotomy, bleeder ligation and re-suturing of the uterus was done in 6 cases (17.6\%), followed by drainage of puss and peritoneal lavage in 5 cases and (14.7\%). unfortunately there were 5 cases $(14.7 \%)$ underwent hysterectomy. 3cases $(8.8 \%)$ of evacuation of broad ligament hematoma. 3 cases (8.8\%) of evacuation of rectus sheath hematoma. 2 cases $(5.9 \%)$ underwent washing blood and clots from the peritoneal cavity. 2 cases (5.9\%) of removal of foreign body. Anterior division of internal artery ligation was done in 2 cases (5.9\%). Tension sutures were done in 2 cases (5.9\%). There was 1 case (2.9\%) of bladder injury repair, 1 case (2.9\%) of Oopherectomy. There was one case (2.9\%) of re suturing of the uterus and 1 case (2.9\%) of removal of packed gauze (Table 2).

With respect to the interval period between Caesarean section and re-laparotomy 13 cases (38.2\%) were reopened within the first 24 hours, 7 cases (20.6\%) in the period between 24 hours and 72 hours and 14 cases (41.2\%) were reopened after 72 hours (Table 3).

Most of the patient had massive blood transfusion there was 9 cases (26.5\%) received 6 - 10 pints, 3 cases (8.8\%) received 11 - 15 pints, 2 cases (5.9\%) received 16-20 pints and 20 cases (58.8\%) received 1 - 5 pints.

Regarding the outcome of re-laparotomy, 22 cases (64.7\%) were alive and well and 6 cases (17.6\%) alive with morbidity (four cases of renal failure manage with dialysis and massive blood transfusion complications in form of pulmonary edema seen in one case). Unfortunately there were 6 cases (17.6\%) of maternal death (Table 4).

Table 2. Distribution of re-laparotomy after Caesarean delivery in Omdurman maternity hospital from June 2014-January 2015 according to the procedure done in re-laparotomy $(\mathrm{N}=34)$.

\begin{tabular}{ccc}
\hline Procedure done in re-laparotomy & Frequency & Percent \\
Hysterectomy & 5 & 14.7 \\
Bleeder ligation \& re suturing the uterus & 6 & 17.6 \\
Anterior division of Internal iliac artery ligation & 2 & 5.9 \\
Removal of packed gauze & 1 & 2.9 \\
Evacuation of broad ligament haematoma & 3 & 8.8 \\
Evacuation of rectus sheath haematoma & 3 & 8.8 \\
Removal of forgign body & 2 & 14.7 \\
Drainage of pus \& peritoneal lavage & 5 & 5.9 \\
Washing of blood \& colts & 5 & 2.9 \\
Oopherectomy & 2 & 1 \\
Bladder repair & 1 & 2.9 \\
Tensions suture & 2 & 5.9 \\
Resuture of uterus & 34 & 2.9 \\
\hline
\end{tabular}

Table 3. Distribution of re-laparotomy according to the time interval between c/s and re-laparotomy in hours in Omdurman maternity hospital from June 2013-January 2014 ( $\mathrm{N}=34)$.

\begin{tabular}{cccc}
\hline Time interval & Frequency & Percent \\
\hline Within 24 hours & 13 & 38.2 \\
$24-72$ hours & 7 & 14 & 20.6 \\
$>72$ hours & 31.2 \\
Total & 34 & 100.0 \\
\hline
\end{tabular}


Table 4. Distribution of re-laparotomy outcome after Caesarean delivery in Omdurman maternity hospital from June 2014January 2015 according to the $(\mathrm{N}=34)$.

\begin{tabular}{ccc}
\hline The outcomes & Frequency & Percent \\
\hline A life and well & 22 & 64.7 \\
A life with morbidity & 6 & 17.6 \\
Death & 34 & 17.6 \\
Total & 34 & 100.0 \\
\hline
\end{tabular}

\section{Discussion}

The study shows incidence of re-laparotomy after Caesarean section is (0.66\%). This is very high in comparison to others studies because of our short period of the study and (27.1\%) Caesarean section rate. In Dhaka Medical Collage Hospital in Bangladesh in a period of one year in 2007, the incidence of re-laparotomy was (0.63\%) with Caesarean section rate of (48.43\%) [4]. A study from India showed the incidence of Re-laparotomy was (0.33\%) with rate of Caesarean section (34.8\%) [13].

In this study re-laparotomy after Caesarean section was common in the age group between 30 - 34 years (38.2\%), which is different compared to figure in recent study in Dhaka Medical Collage Hospital in Bangladesh where age group is 20 - 25 years (34.1\%) [2].

In this study multipara are common group for re-laparotomy after Caesarean section was (58.8\%) but in Ghana teaching hospital it was common in grandmultipara (62.3\%).

Re-laparotomy was performed in $85.3 \%$ of cases after emergency Caesarean section which usually carried out by available staff raising the question about the training competency and who should Caesarean section? Although elective Caesarean section had some percentage of re-laparotomy (14.7\%), which at least had done under supervision of expertise staff; this finding is compatible with the Indian study [13].

The indications of re-laparotomy after Caesarean section are scarce and stereotyped. We found that hemorrhagic etiology such as bleeding and hematoma are the leading causes of re-laparotomy. In this study internal hemorrhage was the commonest cause (44.1\%) compared with (70.8\%) in study of 113 cases over four years period between 2006-2010 in Turkey [3]. PPH was the second indication of re-laparotomy in this study (14.7\%) which was less than in Bangladesh (45.8\%) [2].

Re-laparotomy for septic complications is special condition that should be evaluated separately. Peritonitis was the indication of re-laparotomy in (14.7\%) which was high than in London study (8.8\%) [14].

Burst abdomen indicated re-laparotomy in this study in (8.8\%) which is high when compared to $(4.17 \%)$ in Ghana study [15].

In this study, 5.9\% underwent re-laparotomy due to rectus sheath hematoma compared to (8.3\%) in Indian study [5]. In this study, re-laparotomy was indicated for removal of foreign body in (2.9\%) compared by (8.3\%) in the study in Bangladesh [4]. Others indications were (2.9\%) for removal of the packed gauze, (2.9\%) of ovarian accident and (2.9\%) of bladder injury in comparison to (9.3\%) in Ghana teaching hospital from 2007-2008 [16].

Regarding the procedures done for the study cases to save the mother's life, Bleeder ligation \& re suturing the uterus was done in (17.6\%) which was high because of lack of experience, compared to (11.1\%) in the study in Bangladesh [2].

Hysterectomy was carried out in (14.7\%) after failed of the conservative surgery compared to (64.8\%) in the study in Bangladesh [2].

Drainage of pus \& peritoneal lavage was done in (14.7\%) compared to (6.2\%) in Turkey study [16]. In this study evacuation of broad ligament hematoma was done in (8.8\%). Evacuation of rectus sheath hematoma was done in (8.8\%) more or less like that seen in Bangladesh study (9.25\%) [2].

Ligation of anterior division of internal iliac arteries was found successful in (5.9\%). In this study removal of foreign body was done in (5.9\%), Removal of packed gauze was done in (2.9\%). Bladder repair was done in (2.9\%) all are similar in others studies.

Post Caesarean section follow up is very important in detection of post operative complications here in this study most cases of re-laparotomy (41.2\%) were done after 72 hours from the Caesarean section where (72.6\%) 
was performed during the first 24 hours in the study in Bangladesh [2].

The entire patient in this study received blood transfusion is (58.8\%). (41.2\%) received massive blood transfusion, compared to (54.3\%) in Saudi Arabia study. [17].

The hospital stay was increased in all patients who underwent Re-laparotomy after Caesarean section. Most of the patients (55.9\%) stayed between 7 - 10 days. compared by (10.7\%) in USA study [18].

Maternal mortality was quite high in patient who required re-laparotomy following Caesarean section. In this study it was (17.6\%) 6 out of 34 compared by (25\%) 6 out of 24 in Bangladesh study and (12.1\%) in India study.

The main cause of the deaths was multiorgans failure due to sepsis in three cases; there were two patients died from coagulation failure and one patient died because of hemorrhagic shock with PPH. Those who survived (64.7\%) of them were alive and well and (17.6\%) were alive with morbidity.

\section{Conclusion}

The majority of re-laparotomy was done after emergency Caesarean section performed by the available staff who might lack skills and experience to perform a safe Caesarean section with safety measures of perfection and infection control. The most common etiology for re-laparotomy after Caesarean section is hemorrhage although sepsis is the main cause for maternal death. Re-laparotomy after Caesarean section was contributing to maternal mortality by $17.6 \%$ from all cases studied.

\section{Recommendations}

Policies, protocols and guidelines are adopted to deal with Caesarean section to reduce the risk of re-laparotomy. Surgical training for all doctors performing Caesarean section, and an approach to demonstration of additional surgical skills to arrest excessive bleeding must be emphasized.

Experienced specialist is involved in all difficult cases and supervision for all surgeries.

Prophylactic antibiotics are offered at Caesarean section with induction of anesthesia. This reduces the risk of maternal infection and improves the standard of service and infection preventions are essential for better outcome.

Active management of third stage of labor is conducted to reduce postpartum hemorrhage and re-laparotomy.

Multidisciplinary team should care about the re-laparotomy patient.

\section{Study Limitation}

- Short period of the study.

- Lack of previous studies.

- The essential standard investigations limits the cases detailed follow up.

- Lack of protocols and guidance for re-laparotomy cases management.

\section{Disclosure}

Nothing is to be disclosed and authors have no conflict of interest.

\section{References}

[1] Alam, M. and Das, S.R. (2012) Relaparotomy in Obstetrics and Gynaecology Department of Faridpur Medical College Hospital. Faridpur Medical College Journal, 7, 75-78.

[2] Salam, R., Sabera, S., Farhna, D. and Sama, A. (2012) Relaparotomy after Caesarean Section in Tertiary Referral Teaching Hospital of Bangladesh. Bangladesh Journal of Obstetrics \& Gynaecology, 24, 39.

[3] Akather, R., Hossnin, T. and Raahid, M. (2011) Relaparotomy after Caesarean Delivery. Journal of Dhaka Medical College, 20, 57-62.

[4] Lurie, S., Sadan, O. and Golan, A. (2007) Relaparotomy after Caesarean Section. European Journal of Obstetrics \& Gynecology and Reproductive Biology, 134, 184-187. http://dx.doi.org/10.1016/j.ejogrb.2006.10.017

[5] (2013) WESES Guidelines for Management of Abdominal Infections.

[6] Unalap, H.R., Kamer, E.K. and Aar, H. (2006) Urgent Abdominal Re-Explorations. World Journal of Emergency Sur- 
gery, 1, 10. http://dx.doi.org/10.1186/1749-7922-1-10

[7] Gedikbasi, A., Akyol, A.E., Bingol, B., Uncu, R., Sargin, A. and Ceylan, Y. (2012) Re-Laparotomy after Caesarean Section: Operative Complications in Surgical Delivery. Archives of Gynecology and Obstetrics, 218-224.

[8] Berghot, T., Stenderup, J.K., Jakobson, A.V., Helm, P. and Lenstrup, C. (2006) Intra Operative Surgical Complication during Caesarean Section. Acta Obstetricia et Gynecologica Scandinavica, 82, 251-256. http://dx.doi.org/10.1034/j.1600-0412.2003.00095.x

[9] Van Ramshorst, G.H., et al. (2010) Abdominal Wound Dehiscence in Adults. World Journal of Surgery, 34, 20-27. http://dx.doi.org/10.1007/s00268-009-0277-y

[10] Anita, K. and Kavita, W. (2005) Emergancy Obstetric Hysterectomy. The Journal of Obstetrics and Gynecology of India, 55, 132-134.

[11] Rauf, S., Nasreen, N., Begum, J., Begum, R. and Begum, A. (2009) Shamsunnahar. Emergency Peripartum Hysterectomy in Developing Country. Journal of Bangladesh Collage of Physicians and Surgeons, 20, 68-75.

[12] Dagupta, S., Pratim, S.P., Ardhana, K., Partha, M. and Karti, M. (2010) Early Re-Operations after Gynaecological and Obstetrical Surgery-A Five Years. The Journal of Obstetrics and Gynecology of India, 60, 507-510. http://dx.doi.org/10.1007/s13224-010-0050-z

[13] Seal, S.L., Kamilya, G. and Bhattacharyya, S.K. (2007) Mukherji and Bhattacharyya AR. Relaparotomy after Caesarean Delivery: Experience from an Indian Teaching Hospital. Journal of Obstetrics and Gynaecology Research, 33, 804-809. http://dx.doi.org/10.1111/j.1447-0756.2007.00660.x

[14] Ginekol, P. (2012) Relaparotomy after Initial Surgery in Obstetric and Gynecologic Operations. 2nd Edition, London, 429-432.

[15] Seffah, J.D. (2005) Re-Laparotomy after Caesarean Section. International Journal of Gynaecology and Obstetric, 88, 253-257. http://dx.doi.org/10.1016/j.ijgo.2004.12.014

[16] Erdal, S.M., Abdulkadir, T., Siddik, E.M., Ender, S.H., Ali, O., Sible, S., et al. (2012) Re-Laparotomy after Initial Surgery in Obstetric and Gynecologic Operations: Analysis of 113 Cases. Ginekologia Polska, 83, 429-432.

[17] Al-Nuaim, L.A., Mustafa, M.S. and Abdel Gader, A.G. (2006) Disseminated Intravascular Coagulation and Massive Haemorrage, Management Dilemma. Saudi Medical Journal, 23, 658-662.

[18] Rachail, T., Dowan, S. and Jostein, P. (2011) Early Post Caesarean Section Complications. International Journal of Gynaecological \& Obsetrics, 45, 167-171. 